\title{
CRÔNICA DE UM MASSACRE ANUNCIADO Eldorado dos Carajás
}

CÉsar Barreira

Professor da Universidade Federal do Ceará, Pesquisador do CNPq e do Nuap/Pronex

$\mathrm{O}$ Brasil, na virada de um milênio, apresenta um cenário de ações diferentes que apontam para um quadro de resoluções de conflitos fora do universo jurídico, em oposição às regras e às convenções deste campo. A máxima do cenário sociopolítico brasileiro, da "justiça pelas próprias mãos", vem varando séculos. No final do século XIX e no início deste, o uso de milícias privadas, de polícias locais, de jagunços e de pistoleiros, poderia ser explicado pela ausência ou fragilidade de um poder judicial. Atualmente, esta lógica parece não ser mais plausível e está mais distante da real compreensão do problema. No meio rural, o uso da violência por parte dos grandes proprietários de terra não é resultado somente de um Estado "impotente", mas parece ser, sobretudo, a afirmação de um poder paralelo que faz coexistir modernidade e arcaísmo, civilização e barbárie. Este poder se reproduz no interior de espaços institucionalizados ou não, com a presença ou não de órgãos de segurança.

Na história sociopolítica brasileira, principalmente das áreas rurais, aparece claramente a versão de uma sociedade conflituosa, permeada de confrontos entre famílias, lutas por terra e disputas pela representação política. Podemos dizer que havia ou que há uma certa aceitação e uma demonstração de simpatia pelas resoluções violentas de conflitos, uma benevolência sobre os crimes de honra, uma tolerância sobre a atuação dos pistoleiros ou jagunços e uma indiferença sobre os massacres e assassinatos de trabalhadores rurais. Os valores de vingança, valentia e coragem têm uma boa base de legitimidade social, tendo como corolário a onipotência e impunidade dos grandes proprietários de terra.
É importante buscar compreender o lugar que ocupam a violência e, especificamente, os homicídios nas sociedades contemporâneas como forma de resoluções dos conflitos sociais. Dentro deste quadro, as principais características do "processo civilizador", definido por Norbert Elias (1994), são negadas com seus ideais e valores. A não totalização de um "processo civilizador" torna o autocontrole tênue, havendo espaço para extravasar emoções e sentimentos agressivos. Não havendo a monopolização da violência, não existe a concentração de armas e homens armados sob única autoridade legitimada. Neste sentido, os genocídios, os assassinatos e as humilhações, tendo como contrapartida o medo, a precaução e a submissão é que dão sentido à desordenada monopolização da violência. Espaços sociais "não pacificados" ou, aparentemente, fora dos limites institucionalizados, transparecem, dando lugar a práticas radicais de resolução de conflitos. Neste sentido, as "questões agrárias" são resolvidas através de agressões físicas não mediadas pela legalidade ou negociação.

Nas sociedades onde não existe uma separação nítida entre o público e o privado, como é o caso da brasileira, é muito difícil a modelação social de indivíduos ou grupos, principalmente de setores pertencentes à classe dominante no chamado "processo civilizador". Tais setores possuem sólidas raízes fincadas em práticas violentas nas resoluções de conflitos interpessoais ou na manutenção do poder econômico e político. As ações ocorrem fora de qualquer base de legalidade. Poderíamos dizer que este quadro, de uma violência difusa, é o resultado de um poder 
judicial frágil acasalado com interesses privados, mantidos secularmente pelo uso da força?

O fulcro temático deste artigo ilustra bem esse contexto. Trata-se de compreender um grave conflito que ocorreu entre as forças de segurança do Estado do Pará (Polícia Militar) e trabalhadores rurais. O campo brasileiro é novamente palco de um cenário importante ocorrido no dia 17 de abril de 1996, quando o governador do Pará "mandou a polícia militar desocupar uma estrada no sul do seu Estado. Saldo da operação de trânsito rodoviário: uma carnificina com duas dezenas de sem-terra mortos e 51 feridos. Os homens e as mulheres atacados na floresta, que deixaram sangue e pedaços de cérebro espalhados pelo chão e pela relva, são esses brasileiros chamados de sem-terra, cidadãos que andam descalços, têm roupas sujas de barro e só costumam ser notícia na forma de cadáver" (Veja, 24/04/96). Este acontecimento, nomeado como o "massacre de Eldorado dos Carajás", será objeto de análise deste artigo.

O genocídio de Eldorado dos Carajás trouxe à tona aspectos importantes e ocultos da estrutura de poder, cujo dado mais aparente é o uso recorrente da violência na reprodução deste cenário político. Outro aspecto importante é que voltam ao palco do meio rural as forças policiais enquanto protagonistas de cenas de violência, confundindo espaço público e privado. Adentraremos, em reflexões, um terreno ainda não muito explorado no Brasil, nos estudos de violência que se referem às causas propriamente políticas desse fenômeno.

\section{UM MASSACRE ANUNCIADO}

Nos últimos anos, os massacres de trabalhadores rurais, as eliminações de adolescentes, as execuções realizadas por "justiceiros", enfim, a escalada dos crimes de mando e dos crimes organizados tornaram-se lugar-comum na sociedade brasileira. Atualmente, pode-se dizer que, ao invés de mortes anunciadas, como ocorreu com diversos líderes camponeses a partir da década de 60 (João Pedro Teixeira, na Paraíba, em 1962; Chico Mendes, no Acre, em 1988; Margarida Alves, na Paraíba, em 1983; João Canuto, no Pará, em 1985) agora são massacres anunciados. ${ }^{1}$ Anunciados na medida em que são precedidos de diversos fatos premonitórios, a exemplo de rumores sobre possíveis conflitos e a presença de conhecidos e temíveis pistoleiros. Este clima gera denúncias e pedidos de proteção aos órgãos de segurança do Estado por parte dos trabalhadores rurais. $\mathrm{O}$ medo e a insegurança fazem parte desse clima, tendo como contrapartida a construção real de uma articulação entre o poder público e o poder privado dos grandes proprietários de terra.

Neste quadro, ocorre o denominado massacre do Eldorado dos Carajás, com todos os elementos para se tornar um fato jornalístico - escandaloso, cruel ou inusitado. O evento é um daqueles "episódios cuja repercussão justifica-se pela revelação de outras questões que não estão propriamente neles" (Rondelli, 1998:146).

Em setembro de 1995, cerca de 3.500 famílias de trabalhadores rurais, organizadas pelo Movimento dos Trabalhadores Rurais Sem Terra - MST, formaram um acampamento à margem da estrada, próximo à Fazenda Macaxeira, reivindicando a desapropriação dessa área. ${ }^{2}$ Para os trabalhadores rurais, esta fazenda era improdutiva. Eles reivindicavam sua desapropriação com base no artigo 184 da Constituição Federal: "Compete à União desapropriar por interesse social, para fins de reforma agrária, o imóvel que não esteja cumprindo sua função social, mediante prévia e justa indenização em títulos da dívida agrária, com cláusulas de preservação do valor real, resgatáveis no prazo de até vinte anos, a partir do segundo ano de emissão, e cuja utilização será definida em lei."

O Instituto Nacional de Colonização e Reforma Agrária - Incra fez a vistoria para desapropriar, mas o laudo atestou que a fazenda era produtiva. Segundo denúncias do MST, este laudo foi conseguido através de um suborno junto ao superintendente do Incra do Estado do Pará. ${ }^{3}$

No dia 05 de março de 1996, as famílias acampadas à margem da rodovia PA-275 decidiram ocupar a fazenda Macaxeira, dando início a novas negociações junto ao Incra. De um lado, os trabalhadores se prepararam para defender-se de uma possível repressão, colocando "homens armados espalhados por todo o acampamento e nas picadas abertas na mata, tocaias compostas sempre por mais de dois homens faziam a vigia dia e noite" (O Estado de S. Paulo, 10/03/96). De outro lado, os fazendeiros fizeram várias reuniões com representantes do governo do Estado do Pará, exigindo a reintegração de posse e denunciando o armamento dos trabalhadores rurais. Segundo o MST, “a Federação dos fazendeiros fez uma reunião com o governador e o secretário de segurança. A Federação levou diversos presidentes dos sindicatos dos fazendeiros da região de Marabá para exigir maior repressão ao MST e entregaram uma lista de 19 pessoas que deveriam desaparecer para 'voltar a paz' na região. Na lista estavam todos os coordenadores do MST no Estado do Pará" (Movimento dos Trabalhadores Rurais Sem Terra, 1999:13). 
Em um contexto de negociação, o presidente do Instituto de Terras do Estado do Pará colocou-se como mediador entre o Incra e os trabalhadores rurais para agilitar o assentamento de 3.500 famílias. Ficou combinado entre as partes que seriam enviadas 12 toneladas de alimentos e 70 caixas de remédios para o acampamento. Nenhuma dessas promessas foi cumprida e, no dia 10 de abril, aproximadamente 1.500 famílias iniciaram uma caminhada para Belém, capital do Estado, a 800 km de distância. Esta marcha tinha como objetivo protestar junto ao governo do Estado pelas promessas não cumpridas, e, principalmente, pela demora no processo de desapropriação da Fazenda Macaxeira. No dia 16 de abril, os trabalhadores resolvem bloquear a estrada PA-150 no km 95, próximo à cidade de Eldorado dos Carajás, exigindo comida e ônibus para continuarem a caminhada. Foram abertas novas negociações, tendo como mediador o comandante da $10^{\underline{a}}$ CIPM/1 ${ }^{\text {a }}$ Cipoma, que prometeu alimento e ônibus. No dia 17 de abril pela manhã, foi dada uma informação de que as negociações estavam canceladas. $\mathrm{O}$ cenário estava então montado e as cartas estavam dadas.

Os trabalhadores voltaram a bloquear a estrada, na altura da denominada curva do S, no Município de Eldorado dos Carajás. Por volta das 16 horas do dia 17 de abril, os trabalhadores rurais foram literalmente cercados: a oeste por policiais do quartel de Parauapebas e a leste por policiais do batalhão de Marabá. Há controvérsias sobre quem atacou primeiro: os trabalhadores jogaram paus e pedras e os PMs chegaram lançando bombas de gás lacrimogêneo. O resultado, entretanto, foi bem preciso: morreram 19 trabalhadores rurais, com 37 perfurações de bala, e 56 ficaram feridos. Segundo o médico legista Nelson Massini, houve tiros na nuca e na testa, indicando assassinato premeditado de sete vítimas. Ficaram nos corpos dos mortos 17 balas e 12 deles apresentaram cortes profundos com foices e facões, provavelmente instrumentos retirados dos próprios trabalhadores rurais. Um teve a cabeça estraçalhada.

A sequiência de mortes é estarrecedora, a começar pela primeira vítima. Consta que o primeiro a morrer foi um deficiente auditivo, que não ouviu o barulho dos tiros. "O primeiro tiro acertou o seu pé direito. 'A gente gritava para ele correr, mas não adiantava. Os soldados chegaram perto e atiraram na cabeça', diz Francisco Clemente de Oliveira, agricultor em Serra Pelada, que testemunhou a morte" (Veja, 24/04/96). Um dos últimos foi um líder do MST, Oziel Pereira, de 17 anos, preso e algemado, que foi morto com um tiro na testa.
Os depoimentos dos que estavam na estrada são chocantes e esclarecedores. Ramiro de Souza, 52 anos, acampado na Fazenda Macaxeira, relata: "Íamos para Marabá. Todo mundo estava alegre esperando os ônibus chegarem. De repente começou o tiroteio. Levei um tiro no ombro. Fiquei com medo e corri umas três a quatro horas. Pousei no mato e voltei no outro dia. Eu não quis morrer. Foi uma traição o que eles fizeram com nós" (Especial, Hoje em Dia, 13/04/97). O medo se mistura a uma negociação rompida e traída. O não cumprimento de uma "palavra dada" e a traição ferem profundamente os valores e a moral camponesa, fato que aponta para a quebra de um pacto, dando os elementos para o início de um conflito.

Uma violência desmesurada e selvagem deu o tom do confronto, como relata Avelino Geminiano, 42 anos, acampado na Fazenda Formosa: "Estava a uns cinco metros de distância quando levei um tiro na canela, virei e levei outro nas costas. Caí no chão e eles dispararam os outros sete tiros. Me acertaram as pernas, o pé, as costas e o peito, me algemaram e levaram para dentro do ônibus. Só não me mataram porque tinha uma repórter lá. Eles colocavam o revólver dentro do meu ouvido e da boca e pediam os nomes dos outros vagabundos. Me levaram depois para a cadeia e só às 4 horas da manhã é que cheguei no hospital. Tenho ainda três balas no corpo" (Especial, Hoje em Dia, 13/04/97). A exacerbação da força, conjugada às ações ilegais, aparece nos tiros em pessoas sem possibilidade de renda, no uso da tortura e classificações previamente construídas, segundo as quais os trabalhadores que reivindicam terra para trabalhar são "vagabundos".

O uso do pronome "eles", no depoimento dos trabalhadores para se referir aos policiais, demonstra a construção de dois mundos: o "nosso" e o dos "outros". O pronome indefinido representa também uma designação atribuída aos policiais sem o reconhecimento da instituição policial. O lugar dos policiais é também negado porque eles são vistos como interlocutores capazes de ações ilegais.

\section{OS ÓRGÃOS DE SEGURANÇA: ENTRE O PÚBLICO E O PRIVADO}

A participação e a ação da Polícia Militar no massacre do Eldorado dos Carajás não é um caso isolado e único, fazendo já parte do lado cruel e pitoresco da nossa história. No meio rural, as milícias privadas dos grandes pro- 
prietários de terra, formadas por jagunços e pistoleiros, confundiam-se sistematicamente com as polícias locais: nas ações e nas ordens. As ordens eram emitidas indiscriminadamente pelos chefes políticos, coronéis-proprietários de terra ou comandos das polícias locais. Todos se colocavam como defensores e representantes da ordem. Nas ações, uma possível separação entre a defesa dos bens públicos e dos bens privados era minimizada. As ações das polícias locais eram restritas à preservação de um patrimônio privado. As invasões de terra não partiam de trabalhadores sem-terra e sim de pares que tentavam ampliar seus domínios. Existia uma perfeita simbiose nas ações das milícias privadas e nas polícias locais, quando se tratava de defesa do patrimônio de um coronel-proprietário de terra pertencente às forças políticas dominantes.

Nos desfechos de conflitos sociais em que a violência surge constantemente, na impossibilidade de serem realizadas negociações ou consensos sociais, aparece o embrião de antigas práticas em novos contextos sociopolíticos. A vulgarização ou a naturalização das ações que envolvem jagunços e pistoleiros vem cada vez mais ocupando espaço no meio rural, acobertadas sob uma auréola de legalidade. Tais ações são classificadas como de defesa da propriedade privada, de despejo de ocupantes ou de "limpeza da área" de pessoas "indesejadas". Essas ações passam a ser um marco na escalada da violência no campo. Se, no início deste século, esses personagens foram constantemente acionados para reforçar o poder econômico e político das oligarquias tradicionais, hoje, nas portas de um novo milênio, são sistematicamente utilizados no reforço de grupos econômicos modernos.

As forças policiais e privadas aparecem conjuntamente nas soluções de conflitos agrários. A Conferência Nacional dos Bispos do Brasil - CNBB, em 1980, fez a seguinte declaração: "Em quase todas as unidades da Federação, sob formas distintas, surgem conflitos entre, de um lado, grandes empresas nacionais e multinacionais, grileiros e fazendeiros e, de outro, posseiros e índios. Violências de toda a ordem se cometem contra esses últimos para expulsá-los da terra. Nessas violências, já se comprovou amplamente, estão envolvidos desde jagunços e pistoleiros profissionais, até forças policiais, oficiais de Justiça e juízes. Não raro observa-se a anomalia gravíssima de composição de forças de jagunços e policiais para executar sentenças de despejo." As denúncias são intermináveis, aparecendo em cena os grandes proprietários, juízes, pistoleiros e policiais.

Quando a polícia é mobilizada, isoladamente, na grande maioria dos casos, ocorrem atos violentos contra as famí- lias trabalhadoras, como consta no documento da Anistia Internacional: "Ofícios da polícia militar usam ordens de expulsão para justificar a destruição da propriedade de camponeses durante os despejos. Numa fazenda no norte de Goiás, Fazenda Vale do Juari, os camponeses foram expulsos da terra em três ocasiões, em 1985, 1986 e 1987, seguindo ordens do juiz estadual. Em todas as vezes, a polícia ateou fogo às casas do povoado. Mais tarde, o mesmo juiz declarou que o caso não competia a sua jurisdição e admitiu que sua ordem de expulsão havia sido inválida" (Anistia Internacional, 1978:4). Nestas ações citadas, a polícia contou com a autorização do juiz, e, em muitos casos, age sem nenhuma autorização judicial.

A Comissão Parlamentar de Inquérito da Violência no Campo Brasileiro apontou um aspecto importante, nesta escalada da violência, que é a sofisticação das ações: "Nos anos 70, até meados de 80, a violência física caracterizava-se basicamente pela contratação de pistoleiros por parte dos latifundiários, que assassinavam as lideranças dos trabalhadores, agentes pastorais, advogados, padres, etc. $\mathrm{Na}$ medida em que os trabalhadores foram se organizando, a figura do pistoleiro já não conseguiu mais resolver o 'problema'. Passou-se à utilização das forças repressivas da polícia militar que também se especializou neste tipo de repressão. Mas, em muitas regiões, nem o serviço destas forças tem resolvido o 'problema'. Começou a ser utilizada a organização de grupos paramilitares, muitas vezes treinados e comandados por ex-oficiais" (Relatório Final Aditivo, CPI da Violência no Campo Brasileiro).

No contexto de justificação e complexidade dos aparelhos repressivos, fora de um estado de direito, ganha destaque a visibilidade que é dada às ações ilegais. Atualmente, os pistoleiros não só executam "serviços" de mortes anunciadas, como também seus "serviços" são publicados nos principais jornais nacionais para dissolver litígios, são resolvidos, como escrito à margem da lei, negando o universo jurídico, as regras e as convenções do campo jurídico. "Assustados com a organização dos lavradores sem-terra, fazendeiros de Mato Grosso contratam empresas clandestinas, que atuam como verdadeiras milícias, formadas por ex-policiais e pistoleiros de aluguel, que cobram até $\mathrm{R} \$ 50$ mil para garantir a limpeza da área" (Jornal do Brasil, 15/10/95). Os "serviços" dos matadores de aluguel são divulgados sem que haja nenhuma atitude dos "órgãos de segurança", enquanto as manifestações, as caminhadas camponesas, continuam sendo tratadas como caso de polícia.

As denúncias registradas logo após o massacre do Eldorado dos Carajás - de que os proprietários de terra da re- 
gião se armaram para defender suas terras e que tinha ocorrido uma coleta de dinheiro para financiar a Polícia Militar para reprimir o MST - enquadram-se em uma prática política de não separação entre uma instância pública de uma particular. Quando o Ministério Público do Pará diz que vai investigar os fazendeiros da região de Curionópolis, Eldorado dos Carajás e Parauapebas para saber se eles deram "apoio logístico à Polícia Militar na operação" e se "tradicionalmente eles costumam dar apoio à Polícia Militar para viabilizar outras operações policiais", traz à tona uma prática costumeira. Os investigadores responsáveis pelo caso "comentam reservadamente que é comum os fazendeiros doarem gasolina, meio de transporte e alimentos aos destacamentos da Polícia Militar" (Folha de S.Paulo, 27/04/96). Logo em seguida, surgem as justificativas que apontam que a "falta de recursos faz com que o trabalho da polícia militar dependa da colaboração dos fazendeiros. Com isso, as ações oficiais de policiais muitas vezes só são possíveis com o apoio de empresários rurais. Nas horas de folga, os policiais militares são chamados para fazer segurança privada e resolver conflitos com posseiros. Pelo menos três policiais militares já foram processados por homicídio a mando de fazendeiros locais" (Folha de S.Paulo, 27/04/96). Estes trabalhos extras são justificados pelo baixo salário dos policiais. ${ }^{4}$

O componente de ilegalidade da operação - policiais sem identificação, armas retiradas do quartel sem registro - não consegue encobrir um dado forte da ação, que é a articulação entre as forças privadas e públicas da repressão. E a operação passa a ser julgada dentro dos aspectos mais aparentes como "desmando do comando local". As transferências de responsabilidade, colocadas sempre nos setores subalternos, passam a dar a tônica das explicações justificadoras de violência.

O Presidente da República ordena "que ponham na cadeia, e já, o responsável, ou ninguém vai mais acreditar neste país" ou "tenho a convicção de que, desta vez, os culpados serão julgados mesmo". O governador do Estado do Pará afirma que "independentemente de quem seja o culpado, ele será responsabilizado criminalmente" ou "ninguém tem mais interesse do que eu em que as investigações sejam rápidas e perfeitas. É previsível que um inquérito que envolva 155 militares numa situação trágica apresente problemas, mas podem ser corrigidos". E responsabiliza diretamente o comandante da Polícia, afirmando que a instituição "tem agido de maneira correta. Comandante Mário Pantoja (responsável pela operação) é que agiu de maneira incorreta".
Neste processo de transferência, existe uma clara construção de três níveis ou três instâncias: um primeiro é composto pelos governos federal e estadual, o segundo pelos comandos das polícias e o terceiro pelos autores materiais da ação - a Polícia Militar. Se os comandos locais passam a ser os principais responsáveis, estes, por outro lado, assumem a perda de um controle das tropas, passando a culpa, neste sentido, para os policiais subalternos que "extrapolaram nas suas ações". A conclusão é que houve "transgressões da disciplina militar" por parte dos 155 policiais atuantes na "operação" que resultaram no massacre dos 19 trabalhadores rurais. Prevalecem, no final, simplesmente afirmações lacônicas, como "foi uma ação desastrosa".

\section{CONFRONTO ENTRE DUAS ORDENS}

No massacre do Eldorado, aparecem o confronto e a convivência entre duas ordens. Por um lado, a luta dos trabalhadores rurais por terra, por direitos e por uma cidadania. Por outro lado, um grupo de proprietários de terra que tentam manter seus bens fazendo uso de uma determinada justiça ou de determinadas leis. Esta prática tem como apanágio a utilização de violência, colocando como principais protagonistas as polícias locais e o sistema de pistolagem. No conflito do Eldorado dos Carajás, a reforma agrária aparece como o pano de fundo ou mesmo como palco de um cenário que tem na concentração de terra brasileira, uma das mais altas do mundo, um grande ingrediente. Acampamento, ocupação e marcha são os principais elementos desta longa caminhada dos trabalhadores rurais por uma reforma agrária. Neste percurso, os trabalhadores rurais fazem uso de métodos pacíficos e violentos, legais e ilegais, em função de circunstâncias internas e externas ao grupo. O nível de organização do grupo e as condições de uma justificativa aceita socialmente são os balizadores da natureza das ações. A aceitação social decorre de promessas não cumpridas, pelo governo ou pelos proprietários de terra; e das condições socioeconômicas dos trabalhadores rurais, que implicam forte apelo popular.

As ações dos trabalhadores rurais estão geralmente circunscritas a dois aspectos: são em sua maioria anunciadas previamente e se desenvolvem dentro de fortes traços ritualizados, como demonstra o massacre. O acampamento à margem da estrada PA-275, próximo à Fazenda Macaxeira, localizada perto da cidade de Curionópolis, com suas "lonas pretas", o que já se tornou uma marca do 
MST, reivindicava a desapropriação da fazenda. O processo de ocupação da fazenda, como segunda etapa, era a resposta à morosidade da ação do governo. Por último, surgiu a marcha ou caminhada como momento que dava visibilidade à reivindicação, retirando-a de uma dimensão puramente local. As marchas, nesta dimensão, vão angariando adeptos ou simpatizantes ao longo do trajeto, como também deixam claro o interlocutor na negociação que é o poder estadual. ${ }^{5}$

As manifestações camponesas, com seus rituais, representam um momento de um cerimonial complexo e importante. As reuniões que antecedem as mobilizações têm um caráter democrático de um tempo vivido lentamente. $\mathrm{O}$ uso de bandeiras, geralmente coloridas, e a presença forte de cânticos e hinos marcam o lado festivo e alegre. Como já foi mencionado, "íamos para Marabá. Todo mundo estava alegre esperando os ônibus chegarem." Geralmente, as mobilizações se confundem com festa, revelando um lado descontraído e aventureiro. O perigo e o medo desaparecem, por alguns instantes, com os militantes inebriados por um clima festivo e de conquista de objetivos. Estes, às vezes, não são muito claros, podendo ser uma terra para trabalhar, a recuperação ou reafirmação de um direito adquirido, a busca de um reconhecimento de um lugar no terreno da cidadania, a conquista de aspectos mais imediatos como água e comida ou, simplesmente, a esperança de paz para continuar vivendo. Estes objetivos são, em grande parte, balizados pelo direito a ter direitos. A presença constante das mulheres e das crianças nas manifestações não só atribui um forte apelo social às manifestações, como representa, em boa medida, uma continuidade do cotidiano. As marchas representam uma caminhada para pressionar as autoridades, como meio para atingir um fim, e uma caminhada que faz parte do deslocamento constante em busca de novas terras ou de uma terra para trabalhar.

O caráter ritualizado das manifestações camponesas nos acampamentos, ocupações e marchas denota um forte sentimento de apelo social, mas também uma reafirmação da justeza e legalidade de suas ações. O lado escondido das tocaias dava a dimensão da força e do perigo que representavam os movimentos camponeses fora dos espaços institucionalizados. Atualmente, é a visibilidade e a divulgação que fornecem o contraponto de uma situação adversa. Contra uma situação adversa, somente a aceitação social torna possível uma reversão deste quadro, tendo-se em conta a clara percepção, por parte dos camponeses, do jogo de força, contrariamente às afirmações de que os camponeses não têm compreensão de um quadro político mais amplo.

No conflito do Eldorado dos Carajás, entrecruzam-se duas táticas de momentos históricos diversos. Inicialmente, os camponeses, organizados pelo Movimento dos Trabalhadores Rurais Sem Terra - MST, usam de uma ação costumeira, que é caminhar readaptando-o aos novos conteúdos políticos, tendo em vista pressionar o governo. Os novos conteúdos aparecem na ampla visibilidade e divulgação dadas à marcha, antecedida de um acampamento de uma ocupação e rodadas de negociação com interlocutores que fazem parte do campo institucional.

De outro lado, os grandes proprietários de terra, organizados pela Federação dos Fazendeiros do Estado do Pará, usam como escudo as forças armadas, antigas aliadas. A força e a violência aparecem novamente em cena para conter possível ampliação dos espaços de contestação dos camponeses. Antigos atores reproduzem táticas conhecidas secularmente, mesmo que, do contingente, desnudemse somente os policiais militares do confronto direto do massacre, geralmente praças subalternos. Este confronto tem que ser analisado no âmbito das correlações de forças envolvendo os grandes proprietários de terra, tendo ao seu lado os órgãos de segurança e os trabalhadores rurais, com uma boa base de legitimidade social.

Logo após o confronto entre os trabalhadores rurais e a Polícia Militar, que foi de imediato classificado como massacre, surgiram as manchetes jornalísticas com forte apelo social:

- "Ataque foi preparado com antecedência" (O Liberal, 09/05/96);

- "Sangue em Eldorado" (Veja, 24/04/96);

- "Apesar de tudo, na Macaxeira ainda tem sorriso de criança” (Diário do Pará, 19/05/96);

- "Lista oficial dos 19 mortos no massacre do Pará é divulgada pela polícia civil após cinco dias” (O Povo, 23/04/96);

- "Igreja manda celebrar missa em todo país" (O Povo, 23/04/96);

- "Mortes de Eldorados dominam protesto de servidores públicos" (Diário do Nordeste, 20/04/96).

As matérias mantinham um misto de denúncia e de apelo social, numa tentativa de postergar, como diz Norbert Elias, "a enorme capacidade humana para esquecer coisas dolorosas, sobretudo se aconteceram a outras pessoas relativamente impotentes" (Elias, 1997:269).

Este massacre trouxe, pode-se dizer, um sentimento de indignação em larga escala, tendo uma ampla cobertura 
dos meios de comunicação. Neste clima favorável, com o governo debilitado socialmente e os proprietários de terra acuados, os camponeses, numa clara percepção do quadro político, pressionam os poderes públicos para concretizar vitórias. Tais vitórias aparecem no reconhecimento da justeza e legalidade do movimento, como também em ganhos concretos. A justeza e legalidade são estampadas em sucessivas manchetes: "FHC pede cadeia para o responsável pela chacina e admite que estrutura agrária está ultrapassada" (O Povo, 21/04/96); "Fazendeiros e PMs podem estar ligados ao massacre do Pará" (Diário do Nordeste, 27/04/96); ou "Senado cria comissão para apurar chacina no Pará" (Diário do Nordeste, 19/04/96).

As vitórias concretas apareceram quando a Assembléia Legislativa do Pará aprovou uma pensão especial de R \$ 300,00 por mês para os dependentes dos 19 mortos no massacre e quando a Fazenda Macaxeira foi desapropriada. A pensão especial, aprovada no dia 27 de junho de 1996, dois meses após o conflito, é a confirmação, por parte do Estado, de sua responsabilidade nas mortes. Para um líder dos camponeses, "o assentamento definitivo na Macaxeira tem um valor simbólico para o MST. Foi a primeira fazenda da região, berço do trabalho escravo. Vamos quebrar o tabu da reforma agrária com esse assentamento, por isso os fazendeiros são tão raivosos, por isso patrocinaram o massacre. Mas vamos resistir" (Jornal do Brasil, 22/09/96). A Fazenda Macaxeira foi rebatizada de "Assentamento 17 de abril", em homenagem aos trabalhadores mortos no conflito.

Este massacre traz à tona, novamente, a impunidade que marca a violência no campo. Predomina a avaliação que será mais um homicídio, desta vez coletivo, sem culpado e sem punição. Os inquéritos - militar e civil - abertos para apurar o massacre contêm muitas falhas. Tais falhas, segundo vários especialistas, levam a favorecer uma possível absolvição dos culpados. As principais falhas foram: apenas 55 dos 155 policiais militares envolvidos foram interrogados, não se realizaram exames para detectar resíduos de pólvora nas mãos dos PMs, removeram-se os corpos antes da chegada da perícia e o Ministério Público ofereceu denúncia genérica contra os 155 PMs que participaram da operação, dizendo-se impossibilitado de individualizar as condutas.

Logo após o massacre, predominou a versão de que os culpados não serão punidos, como expressou o diretor da Human Rights Watch/Americas no Brasil. "Para dizer se os responsáveis serão punidos, eu me basearia no passado. E, fazendo isso, diria que é muito provável que o caso não seja apurado e os responsáveis punidos" (O Povo, 21/04/96).

Para a Comissão Pastoral da Terra (CPT), entidade ligada à CNBB, o maior foco de impunidade no campo é o Estado do Pará. De 1985 a 1998, foram assassinadas 225 pessoas em disputas de terras no Estado e somente cinco casos resultaram em julgamentos com a condenação de três assassinos, entre eles um ex-policial, e de dois intermediários. Depois de três anos da chacina de Eldorado de Carajás, nenhum dos acusados está preso e todos continuam exercendo as suas funções de policiais.

Nas missas celebradas em sufrágio dos mortos de Eldorado, a política e a fé misturavam-se no refrão "Deus nos livre da impunidade do massacre".

No processo denominado de Eldorado dos Carajás, foram denunciados inicialmente 155 policiais, sendo oito oficiais e 147 praças (sargentos, cabos e soldados), além de quatro civis. Durante a instrução processual, um soldado e um civil não foram encontrados, sendo citados por edital, suspenso o processo e prazo processional, discutida à revelia. Um soldado está sendo processado separadamente por haver dúvida quanto à sua integridade mental. Finalmente, estão pronunciados 153 policiais militares e três civis. Depois de vários adiamentos, o julgamento foi marcado para a segunda quinzena de agosto de 1999, na comarca de Belém.

Durante a elaboração deste processo e as diversas marcações do julgamento, os proprietários de terra tiveram grande poder de interferência. O primeiro momento foi fortemente marcado pelas "falhas ou incorreções" das provas que subsidiariam o processo. No segundo momento, o juiz-auditor da justiça militar do Pará "rejeita a denúncia". Este ato gerou uma polêmica no campo jurídico com afirmações contrárias a esta postura: "Em seu despacho, o juiz militar deveria apenas ter se declarado incompetente para julgar o processo, encaminhando-o para a justiça comum" ou "se o juiz militar não é competente para receber a denúncia, também não é competente para rejeitá-la" (Folha de S.Paulo, 24/08/96). No momento do "julgamento", este é deslocado de várias comarcas, como também sofre sucessivos adiamentos. Como a comarca de Curianópolis, responsável por Eldorado dos Carajás, não possuía uma infra-estrutura adequada, o julgamento foi marcado para Marabá (657 km, ao sul de Belém). O Ministério Público do Pará pediu a transferência do julgamento para Belém, alegando possíveis interferências no seu resultado em função do envolvimento dos policiais militares na região e da proximidade com os jurados. 
Corroborando essas preocupações, foi assassinado em Marabá um fotógrafo que testemunhou o massacre. Outro momento foi a composição do corpo de jurados. As ligações dos jurados com o comércio e com os ruralistas locais dão o contorno de uma possível parcialidade no julgamento. Tais ligações têm um forte aliado, que é o medo expresso pelos jurados: "Morro de medo dessas coisas"; "Temor sempre se tem, temor de retaliação"; ou "No sul do Pará, a gente diz que não, mas existe medo" (depoimentos à Folha de S.Paulo, 11/11/98).

Nessa configuração, a impunidade dos criminosos provavelmente será reafirmada. O genocídio de Eldorado dos Carajás, que trouxe à tona aspectos ocultos da estrutura de poder, pode também ser um marco no processo de inversão desta impunidade e no processo de exclusão social de uma expressiva força de trabalho. Tal exclusão social imposta aos trabalhadores rurais é substituída pela exclusão física, por meio de chacinas e genocídios.

O massacre de Eldorado dos Carajás, desnudando o lado arcaico e tradicional das relações políticas e econômicas do campo, é o outro lado da moeda do capitalismo moderno - o que mostra não só a necessidade de uma mudança na estrutura agrária, mas também o poder do atraso, da onipotência e impunidade dos grandes proprietários de terra que ainda continuam ditando as regras do jogo no meio rural brasileiro.

\section{NOTAS}

1. Em 1992, foram assassinados 111 presos na Casa de Detenção do Carandiru, no Estado de São Paulo. Neste mesmo ano, ocorreram dois grandes massacres no Estado do Rio de Janeiro: um que ficou conhecido como chacina da Candelária, quando oito jovens foram assassinados enquanto dormiam perto da igreja da Candelária, no centro da cidade; o outro, denominado massacre do Vigário Geral, em que 21 moradores da favela que possui este nome foram metralhados e mortos. No meio rural, além do massacre de Eldorado dos Carajás, que será objeto de análise deste artigo, nove trabalhadores rurais foram assassinados em 1995, em Corumbiara, no Estado de Roraima. Em todos estes acontecimentos, a participação dos órgãos de segurança é o dado comum. Nos últimos anos, têm ocorrido chacinas de famílias pobres, principalmente nas cidades de São Paulo e do Rio de Janeiro, tendo sempre como explicação "problemas de tráfico de drogas". Ganham cada vez mais visibilidade os crimes por encomenda ou crimes de pistolagem, que deixam de ser um fenômeno rural para ganhar os espaços urbanos. Por último, nesta escalada de assassinatos, há os crimes cometidos por "justiceiros", geralmente a mando de comerciantes, que eliminam pessoas "indesejáveis" em algumas das grandes cidades brasileiras, em nome de uma possível insegurança.

2. "Complexo Macaxeira é uma área de 42.558 hectares, situada entre os municípios de Eldorado dos Carajás e Curianópolis, localizada no lado esquerdo da rodovia estadual PA-275. O complexo, inicialmente, era composto por quatro grandes áreas: Castanhal Macaxeira, Castanhal Fundos de Macaxeira, Castanhal Volta do Rio e Castanhal Grota Verde. Hoje este complexo está dividido em 13 diferentes imóveis rurais improdutivos" (Movimento dos Trabalhadores Rurais Sem Terra, 1999:12).

3. Esse superintendente foi exonerado logo após este laudo e, segundo consta, o motivo deste ato foi o suborno.

4. Um soldado da polícia militar da região recebe cerca de $\mathrm{R} \$ 300,00$ por mês. 5. A "marcha nacional" realizada em 1996, organizada pelo MST e que partiu de diversos lugares em direção a Brasília, incorporava claramente estes princípios e objetivos. Nesta marcha, o interlocutor na negociação era o poder central.

\section{REFERÊNCIAS BIBLIOGRÁFICAS}

ANISTIA INTERNACIONAL. Boletim mensal. Série Brasil: Documento. Londres, set. 1978.

BARREIRA, C. Trilhas e atalhos do poder: conflitos sociais no sertão. Rio de Janeiro, Rio Fundo Editora, 1992.

Crimes por encomenda: violência e pistolagem no cenário brasileiro. Rio de Janeiro, Relume Dumará, 1998.

COMISSÃO PASTORAL DA TERRA. Conflitos no campo - Brasil 1994 Goiânia, 1995

COUTINHO, E. "A questão do herói-sujeito em cabra marcado para morrer". Tempo Social. São Paulo, USP, v.6, n.1-2, jun.1995, p.91-106.

ELIAS, N. O processo civilizador: uma história dos costumes. Rio de Janeiro, Jorge Zahar Editor, 1994.

. Os alemães. Rio de Janeiro, Jorge Zahar Editor, 1997.

HOBSBAWM, E. Pessoas extraordinárias - resistência, rebelião e jazz. São Paulo, Paz e Terra, 1998.

MACHADO, M.L. e MARQUES, J.B. História de um massacre: casa de detenção em São Paulo. São Paulo, Cortez Editora, Ordem dos Advogados do Brasil, 1993.

MARTINS, J. de S. "Linchamento, o lado sombrio da mente conservadora". Tempo Social. São Paulo, USP, v.8, n.2, out.1996, p.11-25.

MOVIMENTO DOS TRABALHADORES RURAIS SEM TERRA. "O massacre de Eldorado dos Carajás - Pará/Brasil”. Caderno de Formação. São Paulo, n.32, 1999.

RONDELLI, E. "Imagens da violência: práticas discursivas". Tempo Social. São Paulo, USP, v.10, n.2, 1998, p.145-157. 